J. Lake Sci. (湖泊科学), 2016, 28(5): 1095-1102

DOI 10. 18307/2016. 0520

(C) 2016 by Journal of Lake Sciences

\title{
洞庭湖湿地植物生活型与生态型”
}

\author{
侯志勇 ${ }^{1}$, 谢永宏 $^{1 * *}$, 陈心胜 ${ }^{1}$, 胡佳宇 ${ }^{1,2}$, 曾 静 $^{1}$, 李 旭 ${ }^{1}$, 潘柏含 ${ }^{1,2}$ \\ (1: 中国科学院亚热带农业生态研究所,农业生态过程重点实验室, 洞庭湖湿地生态系统观测研究站, 长沙 410125) \\ (2: 中国科学院大学, 北京 100049)
}

\begin{abstract}
摘 要: 研究植物生活型和生态型可以深刻解析植物群落结构和其环境的关系, 对研究植物群落的发生、发展以及演替 规律都具有重要意义. 通过对洞庭湖湿地植物群落物种生活型及生态型进行调查研究, 结果表明: 洞庭湖湿地植物主要 生长型为草本植物, 其次为藤本植物, 木本类植物缺乏; 生活型主要为一年生植物, 其次为地下芽和地面芽植物, 高位芽 和地上芽植物最少. 在不同典型群落中, 高位芽和地上芽植物在不同群落中所占比重随着高程的递增而增加, 且相同生 活型在不同群落中所占的比重也随高程的递增而增加. 植物生态型构成中, 水分生态型以湿生植物为主, 土壤 $\mathrm{pH}$ 值生态 型以中性土植物最多, 光照强度生态型以阳性植物为主, 淤积生态型以非淤积植物最多. 洞庭湖湿地不同高程典型植物 群落生态型组成为: 阳性、旱生、中生、碱性, 中性、非淤积型植物主要分布于高、中程区, 淤积植物主要分布于低程区; 阴 性、耐阴性、酸性、碱性、非淤积型植物随高程的递增而递增. 在洞庭湖湿地, 能同时适应洪水和泥沙淤积胁迫的生长型和 生活型所占比例较高. 水分是决定不同植物生态型分布的关键因子, 在湿地高程区分布的物种更多, 植物生态型更丰富. 关键词: 洞庭湖湿地; 植物生活型; 植物生态型
\end{abstract}

\section{Life forms and ecotypes of wetland plants at Lake Dongting wetlands}

\author{
HOU Zhiyong ${ }^{1}$, XIE Yonghong ${ }^{1 * *}$, CHEN Xinsheng ${ }^{1}$, HU Jiayu ${ }^{1,2}$, ZENG Jing ${ }^{1}$, LI Xu ${ }^{1} \&$ PAN Baihan ${ }^{1,2}$ \\ (1: Dongting Lake Station for Wetland Ecosystem Research, Key Laboratory of Agro-ecological Processes in Subtropical Re- \\ gion, Institute of Subtropical Agriculture, Chinese Academy of Sciences, Changsha 410125, P.R.China) \\ (2: University of Chinese Academy of Sciences, Beijing 100049, P.R.China)
}

\begin{abstract}
The relationship between plant community structure and its environment by analyzing plant life forms and plant ecotypes has important significance for the occurrence, development and succession law of plant community. An investigation was made on the species life form and ecotypes of wetland plants in Lake Dongting wetlands. Herbs are the dominant growth form, followed by lianas, but trees are scarce. Therophytes are major life forms, followed by geophytes and hemicryphytes, and phanerophtes and chamaephytes were the least in Lake Dongting wetlands. The proportion of phanerophtes and chamaephytes in different communities and the same life in different plant communities increased with the elevation. Hygrophytes is major ecotype according to water requirement. Neutral soil plant is dominant ecotype based on soil $\mathrm{pH}$ requirement. Heliophytes is dominant ecotype according to light intensity demand. The depositions of plants are major ecotype according to responses sediment ubrial. Heliophytes, xerophyte, mesophyte, alkaline plant, neotrophilous and burial intolerant plant distribute mainly in low-elevation sites. Shade-demanding plant, shade-enduring plant, acid plant, alkaline plant and burial intolerant plant species also increased with elevation. In Lake Dongting wetlands, the proportion of plants which can adapt to both flooding and sedimenting processes simultaneously is high. Water is the key factor determining the plant distribution of different ecotypes. Species and ecotypes were more diverse in intermediate- and high-elevation sites.
\end{abstract}

Keywords: Lake Dongting wetlands; plant life form; plant ecotype

植物生活型是植物对环境适应后在其生理、结构、外部形态上的一种具体表现, 其形成是不同植物对相

* 国家科技支撑计划项目(2014BAC09B03) 和国家科技基础性工作专项( 2013YF111800) 联合资助. 2015-07-27 收 稿; 2015-12-09 收修改稿. 侯志勇(1982 ), 男,硕士,助理研究员; E-mail: hzy2005@ isa.ac.cn.

** 通信作者; E-mail: yonghongxie@163.com. 
同环境条件趋同适应的结果; 相同生活型反映的是植物对环境具有相同或者类似的要求或适应能力 ${ }^{[1-2]}$. 一 个地区的生活型谱可反映该地区的气候特征 ${ }^{[3]}$. 群落的生活型谱可反映各类群落的生境特点, 且建群的优 势植物的生活型往往决定着群落的形态和外貌 ${ }^{[4]}$. 生态型是指同一物种内因适应不同生境而表现出具有一 定结构或功能差异的不同类群, 生态型分化是物种进化的基础, 生态型的研究不但可以分析植物种内生态 适应的形式, 以及了解种内分化定型的过程和原因, 而且对研究物种的进化有重要意义 ${ }^{[5]}$. 通过植物生活型 和生态型分析可以深刻解析植物群落结构及其与环境的关系, 并且不同生活型对应不同的地理起源, 这对 研究植物群落的发生、发展以及演替规律都具有重要意义 ${ }^{[6-10]}$.

洞庭湖是我国第二大淡水湖泊, 为长江流域最为典型的吞吐型通江湖泊, 它不但具有调蓄洪水、净化水 质、沟通航运的重要功能, 同时还对保护生物多样性和改善生态环境等具有重要价值 ${ }^{[1]}$. 由于自然和人为 干扰等多重因素的综合影响, 产生了湿地面积不断萎缩、湿地植物群落遭到破坏、湿地生物多样性下降等一 系列生态环境问题. 本研究主要从植物的生活型与生态型出发, 分析洞庭湖湿地植物生活型的分类及生态 型的组成结构,为研究洞庭湖湿地植被发生、发展及演替提供参考依据.

\section{1 研究区概况及研究方法}

\section{1 研究区概况}

洞庭湖 $\left(28^{\circ} 30^{\prime} \sim 29^{\circ} 31^{\prime} \mathrm{N}, 111^{\circ} 40^{\prime} \sim 113^{\circ} 10^{\prime} \mathrm{E}\right)$ 位于湖南省东北部, 长江中游荆江段南岸, 分为东洞庭 湖、横岭湖、南洞庭湖和西洞庭湖, 现有湿地面积约 $1.52 \times 10^{4} \mathrm{~km}^{2}$. 洞庭湖承担着调蓄长江和湖南 “四水” (湘、资、沅、澧) 的重要任务, 素有 “长江之肾” 的美誉. 洞庭湖区为冲积平原, 平均海拔低于 $40 \mathrm{~m}$, 面积为 $18780 \mathrm{~km}^{2}$, 天然湖泊面积 $2625 \mathrm{~km}^{2}$. 湖区属亚热带季风性气候, 春、夏冷暖气流交替频繁, 夏、秋晴热少雨, 秋寒偏旱. 多年平均气温 $16.5 \sim 17.0^{\circ} \mathrm{C}, 1$ 月平均气温 $3.8 \sim 4.7^{\circ} \mathrm{C}$; 7 月平均气温 $29^{\circ} \mathrm{C}$ 左右, 年平均降水量 $1250 \sim 1450 \mathrm{~mm}$, 无霜期 $260 \sim 280 \mathrm{~d}$, 年平均湿度 $80 \%$ 。

洞庭湖湿地作为东北亚冬候鸟重要栖息地, 生物多样性极为丰富, 有高等植物 66 科 182 属 265 种. 以 被子植物为主, 分别占洞庭湖湿地植被科、属、种的 $89 \%$ 、96\% 和 $97 \%$; 偋类植物其次, 共有 7 科 8 属 9 种 ${ }^{[12]}$. 草本植物所占比例达 $97.9 \%$, 木本植物缺乏, 仅有美洲黑杨 ( Populus nigra) 、鸡婆柳 ( Salix triandroides)、旱柳 (Salix matsudana)、无患子 (Sapindus saponaria)、重阳木 (Bischofia polycarpa) 少数几种. 洞庭湖湖岸平缓, 由 岸边向湖心逐渐倾斜, 植物随湖水深度形成不同的植物群落. 植被从空间格局上呈现明显的带状分布: 沉水 植物群落一虉草 (Phalaris arundinacea) 群落一苔草 (Carex sp.) 群落一水苶 (Polygonum hydropiper) 群落+萎蒿 (Artemisia selengensis) + 苔草群落一南荻 ( Triarrhena lutarioriparia) 群落一美洲黑杨或柳群落 ${ }^{[13-14]}$, 在东洞庭 湖高程 $23 \mathrm{~m}$ 以下基本为非植被区, 苔草、水苶和曧草等群落主要分布在高程为 $23.0 \sim 27.0 \mathrm{~m}$ 的区域, 南荻大 部分生长在 $29 \mathrm{~m}$ 高程以上且靠近水域,防护林生长在 $30 \mathrm{~m}$ 高程以上 ${ }^{[15-16]}$.

\section{2 研究方法}

于 2012 年 1-5 月和 10-12 月采用样带和随机样方 (草本样方面积 $1 \mathrm{~m} \times 1 \mathrm{~m}$, 乔木样方面积 $20 \mathrm{~m} \times 20 \mathrm{~m}$ ) 相结合的方法, 对洞庭湖湿地进行植物调查, 本次调查共有 19 个样带 68 个样地 (图 1). 调查地点包括西洞 庭湖、南洞庭湖、横岭湖和东洞庭湖, 即整个洞庭湖. 在每个调查区按照不同水位梯度、不同植被类型、不同 的季节进行调查. 所有植物均采集标本, 主要记录项目包括每个样方中植物种的名称等数量指标以及样地 所在地的经度、纬度和海拔高度等环境因子. 分别对每一种植物做生活型和生态型分类 ${ }^{[17-19]}$. 统计各分类系 统的数量及比率作为其结构分析的数量指标.

\section{3 植物生活型}

植物生活型是植物对综合环境条件的长期适应, 而在外貌上反映出来的植物类 ${ }^{\text {型 }}{ }^{[20-21]}$. 按照 Raunkiaer ${ }^{[17]}$ 对休眠芽在不良季节的着生位置划分的生活型分类系统, 将调查到的洞庭湖湿地植物划分为高 位芽植物、地上芽植物、地面芽植物、地下芽植物和一年生植物 5 类. 植物生长型是指根据植物的可见结构 划分的类群. 植物的生长型反映植物生活的环境条件, 相同的环境条件具有相似的生长型, 是趋同适应的结 果 ${ }^{[22]}$. 根据植物形态学特征 ${ }^{[18]}$, 将调查到的湿地植物划分为乔木、灌木、藤本、草本、水生和寄生几种类型.

\section{4 植物生态型}

根据植物与水分的关系, 将生长在水中的植物统称为水生植物; 生长在潮湿环境中, 不能忍受较长时间 


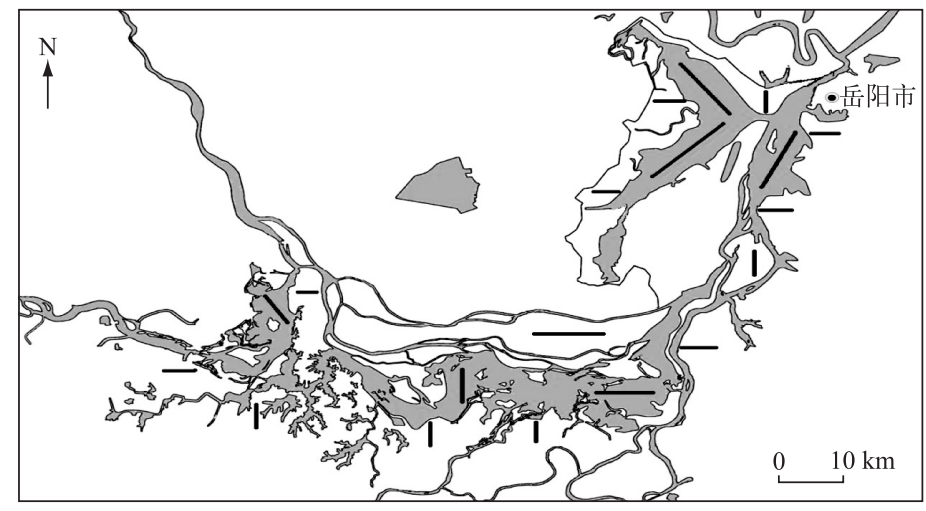

图 1 洞庭湖湿地样带分布

Fig. 1 Distribution of sample belts in Lake Dongting wetlands

水分不足的植物称为湿生植物; 生长在水分条件适中生境中的植物称为中生植物; 生长在干旱环境中, 能长 期耐受干旱环境, 且能维护水分平衡和正常的生长发育的植物称为旱生植物 ${ }^{[23]}$. 根据植物对光照强度的适 应性, 将在强光环境中才能生育健壮, 在荫蔽和弱光条件下生长发育不良的植物, 称为阳性植物; 在较弱的 光照条件下要比在强光下生长得好的植物, 称为阴性植物; 介于阳性和阴性植物之间的植物, 称为耐阴植物. 根据植物对土壤 $\mathrm{pH}$ 值的要求不同, 将只能生长在酸性或强酸性土壤上的植物称为酸性土植物; 将生长在土 壤 $\mathrm{pH}$ 值大于 7.5 的这类植物称为碱性土植物; 适合生长于土壤 $\mathrm{pH}$ 值为中性 ( $\mathrm{pH}$ 值为 $6.5 \sim 7.5$ ) 的这类植物 称为中性土植物 ${ }^{[23]}$. 根据植物对泥沙淤积的适应性, 将在泥沙淤积环境中能生育健壮的植物称为淤积植 物; 将生长在非泥沙淤积环境中的植物称为非淤植物; 将在淤积或非淤积环境中都能生长良好的植物称为 耐淤植物 ${ }^{[24-25]}$.

\section{2 结果与分析}

\section{1 植物生长型及生活型的组成特点}

根据植物的形状类别, 洞庭湖湿地以草本植物为主, 有 202 种, 占洞庭湖湿地植物的 $78.9 \%$, 其中水生植 物 32 种, 占总数的 $12.5 \%$; 藤本植物 10 种, 占总数的 $3.9 \%$; 乔木 7 种, 占总数的 $2.7 \%$; 灌木 4 种, 占总数的 $1.6 \%$; 寄生植物 1 种, 占总数的 $0.4 \%$. 根据休眠芽在度过对生存和生长不利季节时所着生位置距地面高度 的生活型分类系统划分, 洞庭湖湿地有高位芽植物 17 种, 占 $6.6 \%$; 地上芽植物 14 种, 占 $5.5 \%$; 地面芽植物 54 种, 占 $21.1 \%$; 地下芽植物 56 种, 占 $21.9 \%$; 一年生植物 115 种, 占 $44.9 \%$. 可见洞庭湖湿地植物生长型是 以草本植物为主, 其次为藤本植物, 木本植物缺乏; 生活型是以一年生植物为主, 其次为地下芽和地面芽植 物, 高位芽和地上芽植物分布最少 (表 1).

从洞庭湖湿地植物生长型和生活型来看, 能适应湿地生态系统洪水和泥沙淤积这两大主要环境胁迫因 子的生长型和生活型所占比例往往比较高, 湿地植物对洪水和泥沙淤积的适应主要是通过生活史、形态、结 构及生理等方面的调节来实现 ${ }^{[26-27]}$. 洞庭湖湿地水位呈周期性变化,每年的 5-10 月为洪水期,湿地洲滩被 洪水淹没. 湿地植物长期来对湿地环境的适应表现在: 一年生草本植物通过改变生命周期的长度来适应洪 水的威胁, 在洪水来前完成生活史, 种子进人土壤种子库以躲避洪水的干扰; 而多年生草本植物主要是通过 体内形成通气组织和无性繁殖等策略适应环境从而达到物种生存和发展的目的 ${ }^{[28-30]}$, 藤本植物在洞庭湖湿 地集中分布于高海拔南荻群落, 其通过攀爬南荻、芦苇 (Phragmites australis) 等高杆植物缩短被洪水淹没时 间来适应洪水威胁, 洞庭湖分布的木本植物主要为美洲黑杨、旱柳和桑树 (Morus alba), 均具有较强的耐淹 能力 ${ }^{[31]}$. 由于植物的形态类型既受基因控制保持相对稳定, 又受生态环境的影响, 随着生境的变化而变化, 有时还会由一种生活型变为另一种生活型. 如洞庭湖湿地分布的水苶等植物, 《中国植物志》记载其为一年 生植物 ${ }^{[32]}$, 但其在洞庭湖湿地主要是通过地下不定芽繁殖, 以适应生态环境的变化 ${ }^{[33]}$. 
表 1 洞庭湖湿地植物的生长型和生活型特征

Tab.1 Growth form and life form characteristics of plants species in Lake Dongting wetlands

\begin{tabular}{|c|c|c|c|c|c|}
\hline \multicolumn{3}{|c|}{ 生长型 } & \multicolumn{3}{|c|}{ 生活型 } \\
\hline 类型 & 种数 & 比例 $/ \%$ & 类型 & 种数 & 比例 $/ \%$ \\
\hline 草本植物 & 202 & 78.9 & 高位芽植物 & 17 & 6.6 \\
\hline 藤本植物 & 10 & 3.9 & 地上芽植物 & 14 & 5.5 \\
\hline 灌木 & 4 & 1.6 & 地面芽植物 & 54 & 21.1 \\
\hline 木本植物 & 7 & 2.7 & 地下芽植物 & 56 & 21.9 \\
\hline 水生植物 & 32 & 12.5 & 一年生植物 & 115 & 44.9 \\
\hline 寄生植物 & 1 & 0.4 & & & \\
\hline
\end{tabular}

\section{2 植物生态型的组成特点}

由植物对水分主导因子的生态适应而形成的水分生态类型的组成及比例可见, 洞庭湖湿地以湿生型的 种类最多, 为 136 种; 旱生植物 57 种; 中生植物 31 种; 挺水植物 9 种; 浮水植物 9 种; 沉水植物 14 种. 在土壤 $\mathrm{pH}$ 值生态型中, 以中性土植物的种类最多, 为 140 种; 酸性土植物次之, 为 100 种; 碱性土植物最少, 为 16 种. 在 3 个光生态型中, 以阳性植物的种类最多, 为 137 种; 耐阴植物次之, 为 44 种; 阴性植物最少, 为 39 种. 在淤积生态型中, 非淤积植物最多, 为 132 种; 耐淤积植物次之, 为 72 种; 淤积植物最少, 为 52 种. 可见, 在洞 庭湖湿地植物生态型构成中, 水分生态型以湿生植物为主; 土壤 $\mathrm{pH}$ 值生态型以中性土植物最多; 光生态型 以阳性植物为主; 淤积生态型以非淤积植物最多 (图 2).

洞庭湖湿地为典型的通江型湖泊, 湖泊水位呈周期性变化, 形成了独特的 “涨水为湖, 落水为洲” 的湿地 景观, 长期周期性的水文变化使得湖泊洲滩长期处于干湿交替的变化之中. 湿地水文环境是控制湿地植物 水分生态型的构成和分布的关键因子, 湿生植物能适应洞庭湖洲滩湿地干湿交替的水文环境, 故所占比重 大. 研究表明在东洞庭湖湿地土壤 $\mathrm{pH}$ 值随人类活动增加而升高, 酸性土壤主要分布于居住区和旅游地, 该 区域受人类活动干扰比较大, 但工业污染较少; 中性土主要分布于自然保护区, 该区域受人类干扰少, 无工 业污染; 碱性土壤多分布在工业区或农业区 ${ }^{[34]}$. 本研究采样区多为人类活动较少的湖洲, 以中性土壤环境 为主, 通过对环境的长期适应, 故中性土植物种类最多. 此外, 洞庭湖泥沙沉积量大, 特别是在人湖的湘、资、 沅、澧“四水” 和松滋、藕池和太平口 “三口” 及湖中洪道在下游的出口处附近等, 泥沙淤积速率可使湖床地 势抬高 $20 \mathrm{~cm}$, 个别地段可抬高 $1 \mathrm{~m}$ 以上, 总体上来说泥沙淤积强度随高程的增加而减少 ${ }^{[13,35]}$. 调查表明高 程淤积强度不同, 其物种组成也各异, 淤积植物主要分布于低程高淤积强度区, 耐淤积植物主要分布在轻淤 积区, 非淤积植物主要分布于高程无或少淤积区. 泥沙淤积强度较大的区域主要为江河人湖口及湖中洪道 出口等较小区域 ${ }^{[13]}$, 大多数海拔较高区域泥沙淤积强度较轻或无, 可见, 适应这种生境的非淤积植物在洞庭 湖湿地分布更广, 所占比例更大.

\section{3 典型群落类型生活型组成}

洞庭湖湿地植被沿高程呈明显的带状分布, 在不同高程形成不同类型植被. 本研究以分布于洞庭湖不 同高程 (由低至高) 的典型优势群落曧草、水蓼、苔草和南荻 4 种类型为研究对象, 分析不同高程梯度植被生 活型及生态型构成. 不同植物群落中一年生植物最多, 曧草、水苶、苔草和南荻群落一年生植物所占比例分 别为 $15.9 \% 、 22.2 \% 、 20.1 \%$ 和 $28.6 \%$; 各群落地下芽植物所占比例分别为 $3.2 \% 、 4.8 \% 、 14.3 \%$ 和 $15.9 \%$; 地面 芽植物所占比例分别为 $0 、 0 、 3.2 \%$ 和 $14.3 \%$; 地上芽和高位芽植物只在南荻群落有分布, 所占比例分别为 $4.8 \%$ 和 $6.3 \%$ (表 2 ).

由此可见, 在洞庭湖湿地不同植物生活型随着高程升高而增多,一年生植物和地下芽植物在不同高程 都有分布, 随着高程递增地面芽植物开始在苔草和南荻群落分布, 地上芽和高位芽植物只分布于高程区的 南荻群落. 同时, 相同生活型植物在生活型谱中所占的比例也随高程升高而增加, 苔草群落一年生植物比例 低于水蓼群落 (表 2), 这可能和群落特征及优势种有密切的相关性, 苔草群落的建群种苔草主要通过无性克 隆繁殖,群落优势种密度大, 易形成郁闭空间, 不利于其他物种生存, 因此群落生物多样性低. 


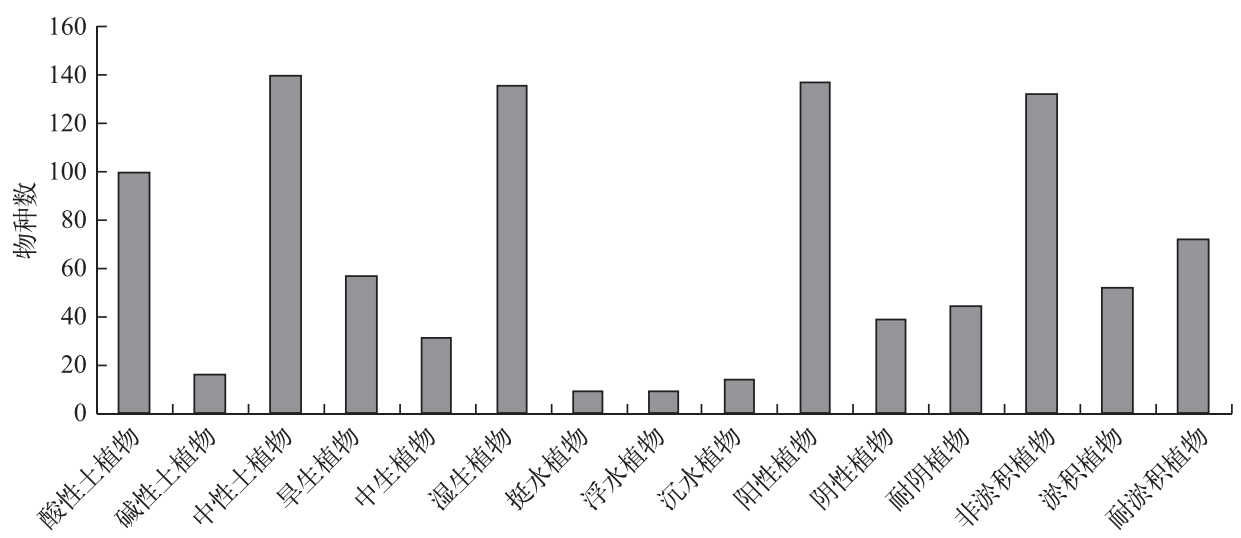

图 2 洞庭湖湿地植物生态型谱

Fig.2 Plant ecotype in Lake Dongting wetlands

表 2 洞庭湖湿地不同高程植物群落生活型谱

Tab.2 Spectrum of plant life form under different elevation plant communities of Lake Dongting wetlands

\begin{tabular}{|c|c|c|c|c|c|c|}
\hline \multirow{2}{*}{ 群落类型 } & \multirow{2}{*}{ 分类单位数 } & \multicolumn{5}{|c|}{ 植物生活型谱 } \\
\hline & & 高位芽 & 地上芽 & 地面芽 & 地下芽 & 一年生植物 \\
\hline \multirow[t]{2}{*}{ 南荻 } & 数量 & 4 & 3 & 9 & 10 & 18 \\
\hline & 占比/\% & 6.3 & 4.8 & 14.3 & 15.9 & 28.6 \\
\hline \multirow[t]{2}{*}{ 苔草 } & 数量 & 0 & 0 & 2 & 9 & 13 \\
\hline & 占比/\% & 0 & 0 & 3.2 & 14.3 & 20.1 \\
\hline \multirow[t]{2}{*}{ 水蓼 } & 数量 & 0 & 0 & 0 & 3 & 14 \\
\hline & 占比 \% \% & 0 & 0 & 0 & 4.8 & 22.2 \\
\hline \multirow[t]{2}{*}{ 嗝草 } & 数量 & 0 & 0 & 0 & 2 & 10 \\
\hline & 占比/\% & 0 & 0 & 0 & 3.2 & 15.9 \\
\hline
\end{tabular}

\section{4 典型植被类型生态型组成}

根据不同物种对光照强度的生态适应所形成的生态型, 洞庭湖典型群落物种生态型组成均表现为以阳 性植物为主, 而阴植物次之, 阴性植物最少. 植物通过对洞庭湖湿地特殊水文环境的长期适应, 形成了以草 本植物为主的植被类型 (如南荻、苔草、水蓼和曧草群落), 草本植物群落密度大, 群落高度相对较低矮, 不利 于阳光进入群落内, 群落底层分布的物种少而单一, 主要为水田碎米荠 (Cardamine lyrata)、肉根毛莨 $(R a-$ nunculus polii) 及碎米荠 (Cardamine hirsuta) 等耐阴和阴性植物, 草本植物的群落特征导致群落组成以阳性 植物为主. 不同高程植物群落阳性植物的分布以南荻群落最多, 苔草群落次之, 虉草群落再次之, 水蓼群落 最少, 呈高中区和低程区阳性植物多、中低程区阳性植物种类少的趋势; 阴性植物和耐阴植物物种数随高程 上升而递增( 图 3).

湿生植物是洞庭湖湿地典型植物群落的主要组成, 能适应洞庭湖湿地干湿交替的水文环境, 故在典型 群落中分布最广, 所占比重最大; 旱生和中生植物只在淹水时间短或不被淹没的高海拔区分布, 其物种数随 海拔的上升而递增; 水生植物在不同群落均有少量分布 (图 3). 南荻群落分布的水生植物为芦苇, 苔草、水 苶和曧草群落分布的水生植物为具刚毛芓荠 (Eleocharis valleculosa), 调查表明芦苇在水深 $10 \mathrm{~cm}$ 以下时才 生长发育良好, 水分必须适宜才能形成群落, 因此在高程低于 $27 \mathrm{~m}$ 时, 水淹时间过长或淹没深度太大, 不适 合芦苇生长 ${ }^{[15]}$, 故只在南荻群落有分布, 而具刚毛荣荠主要通过无性繁殖, 经过长期对洞庭湖湿地环境的适 应,其通过地下芽休眠来适应水位的周期性变化,因此能在低程区的植物群落分布.

根据物种对土壤酸碱性的适应所形成的生态型进行分析发现, 酸性土植物在洞庭湖 4 种典型植被群落 
中的分布随高程梯度递减而减少; 碱性土植物分布于高程相对较高的中、高程区, 且随高程的递减而减少; 中性土植物在洞庭湖典型植被分布为高海拔区的南荻群落最多, 低程区的虉草群落次之, 中程区的苔草群 落和中低程区的水蓼群落分布最少, 呈“V”结构 (图 3).

通过对洞庭湖典型植被群落物种淤积生态型进行统计分析发现, 淤积植物以苔草群落最多, 南荻群落 次之, 融草群落再次之, 水蓼群落最少; 耐淤积和非淤积植物均表现为南荻群落最高, 苔草群落次之, 水蓼和 蒚草群落最少, 物种数随群落分布海拔递减而减少 (图 3 ). 可见在湿地这一特殊水文环境中, 高程区适宜于 更多非淤积型植物分布; 而在低程泥沙淤积严重的区域以淤积植物为主, 耐淤积及非淤积植物分布较少, 且 物种组成相对单一.
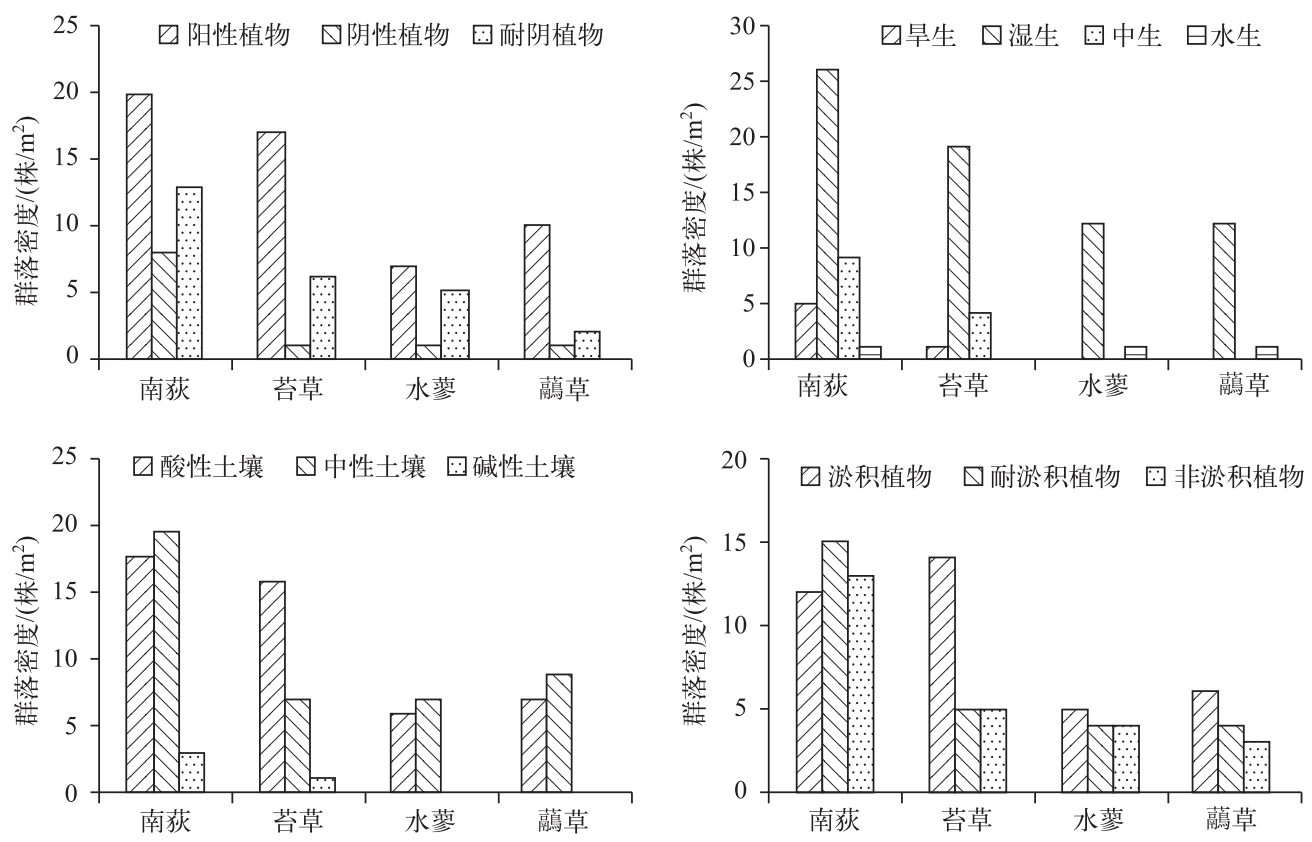

图 3 洞庭湖湿地不同植物群落的生态型组成

Fig.3 Plant ecotypes of different plant communities in Lake Dongting wetlands

\section{3 参考文献}

[ 1 ] Mueller-Dombois D, Ellenberg H. Aims and methods of vegetation ecology. New York: John Wiley \& Sons, 1974: 139-147.

[ 2 ] Whittaker RH. Communities and ecosystems. New York: Macmillan Company, 1970: 6-17.

[ 3 ] Gao Xianming, Chen Lingzhi. The revision of plant life-form system and an analysis of the life-form spectrum of forest plants in warn temperate zone of China. Acta Botanica Sinca, 1998, 40(6) : 553-559(in Chinese with English abstract). [高贤明, 陈灵芝. 植物生活型分类系统的修订及中国暖温带森林植物生活型谱分析. 植物学报, 1998, 40(6): 553-559. ]

[ 4 ] Walter H. Vegetation of the earth and ecological systems of the geo-biosphere (2nd ed.). New York: Springer-Verlag, 1979: 166-169.

[ 5 ] Liu Zhiyan, Chen Beiguang, Xie Zhengsheng et al. Advances in plant ecotype classification. Ecologic Science, 2004,23 (4) : 365-369 (in Chinese with English abstract). [刘志彦, 陈北光, 谢正生等. 植物生态型分类研究进展. 生态科 学, 2004, 23(4) : 365-369.]

[6 ] Sarmiento L, Llambi LD, Escalona A et al. Vegetation patterns, regeneration rates and divergence in an old-field succession of the high tropical Andes. Plant Ecology, 2003, 166: 145-156. 
[ 7 ] Yan Zhongcheng. Ecoform and life form. Bulletin of Biology, 2001, 36(5): 4-5 (in Chinese with English abstract). [ 颜 忠诚. 生态型与生活型. 生物学通报, 2001, 36(5): 4-5.]

[ 8 ] Zhang Muming, Chen Beiguang, Su Zhiyao. Phytocoenological characters of the Castanopsis carlesii forest in north Guangdong. Journal of South China Agricultural University, 2001, 22(3): 9-12 (in Chinese with English abstract). [张木明, 陈北光.苏志尧. 粤北小红栲林的群落特征. 华南农业大学学报, 2001, 22(3): 9-12.]

[ 9 ] Lei Ningfei, Su Zhixian, Song Huixing et al. A comparative study on life-form spectra of evergreen broad-leaved forest in different successions in Jinyun Mountain. Chinese Journal of Applied Ecology, 2002, 13 (3): 267-270 (in Chinese with English abstract). [ 雷泞菲, 苏智先, 宋会兴等. 缙云山常绿阔叶林不同演替阶段植物生活型谱比较研究. 应用生 态学报, 2002, 13(3) : 267-270.]

[10] Bai Yunpeng, Hang Dayong, Dong Yanhong et al. Structural characteristics of Hemiptelea davidii community on Kerqin sandy land. Chinese Journal of Applied Ecology, 2008, 19(2) : 257-260 (in Chinese with English abstract). [ 白云鹏, 韩 大勇, 董艳红等. 科尔沁沙地刺榆群落的结构特征. 应用生态学报, 2008, 19(2): 257-260.]

[11] Xie Yonghong, Wang Kelin, Ren Bo et al. Evolution problems and protection measures of ecological environments in Dongting Lake area. Research of Agricultural Modernization, 2007, 28(6) : 677-681 (in Chinese with English abstract). [谢永宏, 王克林, 任勃等. 洞庭湖生态环境的演变、问题及保护措施. 农业现代化研究, 2007, 28(6): 677-681.]

[12] Hou Zhiyong, Xie Yonghong, Zhao Qihong et al. Status, utilization and conservation of plant resources in Dongting Lake Wetlands. Research of Agricultural Modernization, 2013, 34(2) :181-185 (in Chinese with English abstract). [侯志勇, 谢永宏, 赵启鸿等. 洞庭湖湿地植物资源现状及保护与可持续利用对策. 农业现代化研究, 2013, 34(2): 181-185.]

[13] Xie Yonghong, Chen Xinsheng. Effect of Three-Gorge Project on succession of wetland vegetation in Dongting Lake. Research of Agricultural Modernization, 2008, 29(6): 686-687(in Chinese with English abstract). [谢永宏, 陈心胜. 三峡 工程对洞庭湖湿地植被演替的影响. 农业现代化研究, 2008, 29(6) : 684-687.]

[14] Peng Peiqin. Succession and ecological research proposal of Dongting Lake. Science News, 2007: 7-8( in Chinese). [ 彭佩 钦. 洞庭湖湿地形成演替与湿地生态研究建议. 科学新闻, 2007: 7-8. ]

[15] Zeng Guangming, Long Yong, Liang Jie et al. The spatial distribution and adaptability analysis of vegetation in East Dongting lake wetland based on 3s techniques. Journal of Hunan University, 2013, 40(5) : 86-91 (in Chinese with English abstract). [ 曾光明, 龙勇, 梁婕等. 基于 $3 \mathrm{~S}$ 技术的东洞庭湖湿地植被的分布与适应性分析. 湖南大学学报, $2013, \mathbf{4 0}(5): 86-91$.

[ 16] Zheng JM, Wang LY, Li SY et al. Relationship between community type of wetland plants and site elevation on sandbars of the East Dongting Lake, China. For Stud China, 2009, 11(1) : 44-48.

[17] Raunkiaer C. The life forms of plants and statistical plant geography. New York: Oxford University Press, 1932: 2-104.

[18] Whittaker RH.Communities and ecosystem. New York: Macmillan Company, 1970: 6-17.

[19] Guo Yongbing, Zhang Youde, Qin Tiancai. Division of plant species diversity and ecotype. Environmental Science \& Technology, 2000, 90(Z1): 49-51 (in Chinese with English abstract). [ 郭永兵, 张友德, 秦天才. 植物种内多样性与生态 型的划分. 环境科学与技术, $2000, \mathbf{9 0}(\mathrm{Z1})$ : 49-51.]

[20] Lande R. A quantitative genetic theory of life history evolution. Ecology, 1982, 63: 607-615.

[21] Sarmiento L, Llambi LD, Escalona A et al. Vegetation patterns, regeneration rates and divergence in an old-field succession of the high tropical Andes. Plant Ecology, 2003, 166: 145-156

[22] Ou Yuduan, Su Zhiyao, Li Zhenkui et al. Effects of topographic on the distribution of groud plants with different growth form in montane forests in North GuangDong, China. Chinese Journal of Applied Ecology, 2011, 22(5) : 1107-1113 (in Chinese with English abstract). [欧余端, 苏志尧, 李镇鬼等. 地形因子对粤北山地森林不同生长型地表植物分布格 局的影响. 应用生态学报, 2011, 22(5) : 1107-1113.]

[23] Li Bo. Ecology. Beijing: Higher Education Press, 2003: 126-138(in Chinese). [李博. 生态学. 北京: 高等教育出版 社, 2003: 126-138.]

[24] Maun MA, Elberling H, Angelo D et al. The effects of burial by sand on survival and growth of Pitcher's thistle (Cirisium pitcher) a long Lake Huron. Journal of Coastal Conservation, 1996, 2 : 3-12.

[25] Pan Ying, Xie Yonghong, Chen Xinsheng et al. Adaptation of wetlands plants to sedimentation stress A review. Chinese Journal of Ecology, 2011, 30(1) : 155-161 (in Chinese with English abstract). [潘瑛, 谢永宏, 陈心胜等. 湿地植物 
对泥沙淤积的适应. 生态学杂志, 2011, 30(1) : 155-161.]

[26] Fraser LH, Karnezis JP. A comparative assessment of seeding survival and biomass accumulation for four teen wetland plant species growth under minor water-depth differences. Wetlands, 2005, 25(3) : 520-530.

[27] Luo Wenbo, Xie Yonghong, Song Fengbin. Survival strategies of wetland plants in flooding environments. Chinese Journal of Ecology, 2007, 26(9) : 1478-1485 (in Chinese with English abstract). [罗文泊, 谢永宏, 宋凤斌. 洪水条件下湿地 植物的生存策略. 生态学杂志, 2007, 26(9) : 1478-1485.]

[28] Warwick NWM, Brock MA. Plant reproduction in temporary wetlands: The effects of seasonal timing, depth, and duration of flooding. Aquatic Botany, 2003, 77: 153-167.

[29] Colmer TD. Long-distance transport of gases in plants: A perspective on internal aeration and radial oxygen loss from roots. Plant, Cell and Environment, 2003, 26: 17-36.

[30] Zeng B, Fu TF, Schurr U et al. Different responses of sexual and a sexual reproduction of Arundinella hirta to flooding. Frontiers of Biology in China, 2006, (1): 46-49.

[31] Yang Fan, Liu Weiwei, Deng Wenqiang et al. Feasibility analysis of poplar for the construction of ecological protection forest in the water-level-fluctuating zone of the three gorges reservoir. Resources and Environment in the Yangtze Basin, 2010, 19(2) : 141-146 (in Chinese with English abstract). [杨帆, 刘维暐, 邓文强等. 杨树用于三峡水库消落区生态防护 林建设的可行性分析. 长江流域与资源, 2010, 19(2): 141-146.]

[32] Chinese Academy of Sciences, China Flora Editorial Board ed. Flora Repubulicae Popularis Sinicae. Beijing: Science Press, 2004(in Chinese). [中国科学院《中国植物志》编辑委员会编. 中国植物志. 北京: 科学出版社, 2004.]

[33] Chen XS, Deng ZM, Xie YH et al. Belowground bud banks of four dominant macrophytes along a small-scale elevational gradient in Dongting Lake wetlands, China. Aquatic Botany, 2015, 122: 9-14.

[34] Ou Furong, Lv Dianqing, Zhao Dandan. Effects of the distribution of $\mathrm{pH}$ value on the content of heavy metal in soil of the eastern Dongting lakeside belt. Environmental Science Survey, 2014, 33(5) : 10-13 (in Chinese with English abstract). [欧芙容, 吕殿青, 赵丹丹. 东洞庭湖湖滨带土壤酸碱度的分布及对重金属含量的影响. 环境科学导刊, 2014, 33 (5) : 10-13.]

[35] Jiang Jiahu, Huang Qun, Sun Zhandong. Sediment deposition and the bottomland change research of the Dongting Lake. Yangtze River, 2009, 40(14) : 74-75(in Chinese with English abstract). [姜加虎, 黄群, 孙占东. 洞庭湖泥沙淤积与 洲滩变化研究. 人民长江, 2009, 40(14): 74-75. ] 